\title{
DUAS LEITURAS DE HEGEL: DUAS PROPOSTAS DE ONTOLOGIA
}

\author{
Manfredo Araújo de Oliveira*
}

\begin{abstract}
SINTESE - H. G. Gadamer faz uma leitura do sistema de Hegel a partir de uma critica externa que, diagnosticando corretamente a perda da dimensão da contingência e da historicidade no sistema hegeliano, constrói uma ontologia específica na qual se enraíza, então, a hermenêutica. C. Cirne-Lima faz uma critica interna ao sistema de Hegel, reformulando-o, todo ele, de ponta a ponta, sob o primado de um operador modal deôntico, o dever-ser. Com isso pretende repor a contingência e a historicidade dentro do método e da lógica do sistema. Disso resulta um projeto de sistema, travejado por principios de necessidade deôntica, que tem uma ontologia com caracteristicas próprias.
\end{abstract}

\begin{abstract}
H. G. Gadamer makes an interpretation of Hegel's system, starting from an external critic, which, by means of a correct diagnosis of the loss of the dimension of contingence and historicity in Hegel's system, builds a specific ontology where hermeneutics has its roots. C. Cirne-Lima makes an internal critic to Hegel's system, reformulating it from beginning to end, lead by a deontic modal operator, i.e., the moral obligation. Thus he claims to replace contingence and historicity into the method and the logic of the system. The result is a project of a system supported by principles of deontic necessity, having an ontology with typical characteristics.
\end{abstract}

\section{A. A crítica externa a partir da historicidade: Hans-Georg Gadamer}

Para Gadamer, a hermenêutica não é, como em Dilthey, em primeiro lugar, uma metodologia, ou seja, a metodologia específica das ciências do espírito, mas uma forma nova de entender filosofia enquanto tal. ${ }^{1}$ Ela se situa na tradição póshegeliana de crítica a Hegel e por isto o confronto com Hegel, ${ }^{2}$ explícito ou implícito, é constante no pensamento de Gadamer.

Ele insiste no caráter central da lógica na filosofia hegeliana e a interpreta como a plenificação da tarefa que a filosofia transcendental de Kant abriu para a reflexão filosófica, ou seja, desenvolver a totalidade do saber humano a partir da autoconsciência. O ponto fontal para toda verdade do saber humano é a ação autônoma da autoconsciência autodeterminando-se. Condição de possibilidade para a

* Universidade Federal do Ceará, UFCE.

1 Cf. H. Braun, "Zum Verhältnis von Hermeneutik und Ontologie", in: Hermeneutik und Dialektik II ed. por R. Bubner/K. Cramer/R. Wiehl, Tübingen, 1970, p. 201-218.

2 Cf. H-G. Gadamer, "Die Idee der Hegelschen Logik", in: Neuere Philosophie I, Hegel, Husserl, Heidegger, Tübingen, 1987, p. 65-86.

\begin{tabular}{|l|l|l|l|l|l|} 
VERITAS & Porto Alegre & v. 40 & $\mathrm{n}^{\circ} 160$ & Dezembro 1995 & p. 741-758 \\
\hline
\end{tabular}


realização desta tarefa é a purifíciçção do" "eu empírico" e sua elevação ao "eu transcendental" e, para Hegel, este foi, precisamente, o resultado de sua "fenomenologia do espírito" que mostrou, para a consciência comum, que o eu puro é espírito, portanto, que a verdade do eu é o saber puro, isto é, a lógica enquanto o desenvolvimento do conceito puro em suas determinidades.

O "saber absoluto" é o resultado deste processo de purificação, pois nele ficou claro que o eu não é simplesmente sujeito, mas razão e espírito e com isto todo o real, ${ }^{3}$ o que, para Gadamer, significa que Hegel recupera a tradição platônico-aristotélica da "metafísica do Lógos-Nous", que antecede toda a problemática da autoconsciência da filosofia moderna da subjetividade. ${ }^{4}$ A tarefa da filosofia, como Hegel a entendeu, consistia precisamente em fundamentar esta metafísica no chão do espírito consciente de si mesmo da modernidade, o que significa dizer, segundo Gadamer, que a dialética platônica que Hegel tem diante dos olhos como paradig$\mathrm{ma},{ }^{5}$ sofre, aqui, uma profunda modificação. Hegel chama de "o lógico" o universo das idéias trabalhado por Platão e sua pretensão é explicitar a validade de cada pensamento (portanto, de cada idéia) no contexto de um desenvolvimento sistemático de todos os pensamentos, o que, segundo Gadamer, não pode mais ocorrer no encaminhamento vivo de um diálogo socrático, mas na base da "seqüência metódica da ciência", que, em última instância, se fundamenta na concepção cartesiana de método e se articulou como filosofia transcendental a partir do "princípio da autoconsciência". ${ }^{6}$

Nesta perspectiva, é o desenvolvimento sistemático dos conceitos puros na ciência da lógica que determina o "sistema da ciência" enquanto um todo. É neste contexto que Hegel transforma a lógica da tradição numa verdadeira ciência que levanta a pretensão de explicitar o autêntico método da filosofia:o método dialético. A dialética exprime a grande ousadia dos pensadores eleáticos que, como pri-

3 Segundo Gadamer, o conceito de "vida" constitui o fundo metafisico que sustenta o pensamento especulativo do idealismo alemão e é fundamental no pensamento de Fichte e no pensamento de Hegel. Em contraposição às abstrações do entendimento, como também à particularidade da percepção e da representação, o conceito de vida implica a vinculação com a totalidade, com a infinitude. Cf. H-G. Gadamer, Wahrheit und Methode. Grundzüge einer philosophischen Hermeneutik, 2. ed. Tübingen, 1965, p. 59.

4 É grande mérito de Hegel, segundo Gadamer, ter percebido que o método do saber moderno se entende a si mesmo e se realiza enquanto uma ação estranha numa coisa. Hegel criticou este método a partir da concepção de método dos gregos para quem método é ação da própria coisa, o que, de nenhuma forma significa passividade na concepção do conhecimento. $O$ que se pretende dizer com isto é que a ação e o esforço do sujeito não são algo arbitrário, dependente de intuições casuais, mas o desenvolvimento imanente de um pensamento. Pensar significa precisamente desenvolver uma coisa em suas próprias conseqüências. É isto que, desde os gregos, chamamos de dialética. Cf. H-G. Gadamer, Wahrheit und Methode, op. cit. p. 439-440.

5 Para descrever a natureza do método verdadeiro, que é uma ação da própria coisa, Hegel, segundo Gadamer, se refere fundamentalmente a Platão que gosta de mostrar seu Sócrates em seus diálogos com os discípulos. Dialética nada mais é do que a arte de conversar e sobretudo de descobrir a inadequação das opiniões através das conseqüências do perguntar. Assim, negativamente, dialética é a confusão das opiniōes. Mas esta confusão tem um efeito positivo: ela torna possivel uma verdadeira visão sobre a coisa. Cf. H-G. Gadamer, Wahrheit und Methode, p. 440. 
meiros, no ocidente, se situaram, conseqüentemente, naquilo que exige o pensamento puro, livre de toda perturbação doś sentidos.

Hẹgel, no entanto, considera a dialética platônica como algo negativo sem que ela seja capaz de articular, positivamente, o conhecimento científico, pois nela não há um começo absoluto e nenhuma fundamentação na idéia do saber absoluto. A convicção básica da dialética platônica é que não existe verdade de idéia isolada, as idéias estão sempre imbricadas entre si. O pensamento humano não tem a estrutura de um espírito intuitivo originário e infinito, mas capta o que é sempre no desenvolvimento discursivo de seus pensamentos. Por isto, Lógos para Platão é sempre relação de idéias entre si. ${ }^{\text {? }}$

No entanto, Platão não distinguiu, com plena clareza, as determinações reflexivas puras que dizem respeito ao Lógos enquanto tal e os conceitos cosmológicos que articulam determinadas regiões do ser. Aqui precisamente entra a dialética hegeliana: ela pretende desenvolver, sistematicamente, todos os conceitos fundamentais de nosso pensamento, pois eles são todos determinações do cohceito, ${ }^{8}$ isto é, do Absoluto. A tarefa do método é justamente vincular todos os conceitos entre si. Assim, a doutrina do "conceito" articula a plenitude da unidade de ser e pensar. ${ }^{9}$

A nova cientificidade que caracteriza a lógica consiste em que ela, tomando a lógica transcendental como ponto de partida, desenvolve o universo dos conceitos do entendimento enquanto o todo da ciência. Só que, aqui, na dialética, as categorias não são entendidas como puras determinações formais da sentença, mas levantam a pretensão de, na forma da sentença, captar a ordem do $\operatorname{ser}^{10}$ e o método dialético significa a garantia de um desenvolvimento não arbitrário dos pensamentos; ao contrário, seu progresso se revela como imanentemente necessário.

Todas as categorias são determinidades do conteúdo do saber, isto é, determinidades do conceito. Na medida em que o conteúdo deve desenvolver-se na multiplicidade de suas determinidades para poder atingir a verdade do conceito, a ciência tem que começar com a categoria menos determinada. Aqui está a "medida", o critério para a exposição categorial e, portanto, para a construção da lógica: começar com o mais universal, isto é, com o menos determinado e prosseguir até o conteúdo pleno do conceito, explanando todo o conteúdo do pensamento.

Para Gadamer, Hegel é plenamente conseqüente em sua pretensão. A questão de fundo deste projeto é que ele leva à plenitude a "tendência objetivante" da razão

7 Cf. H-G. Gadamer, "Hegel und die antike Dialektik", in: Neuere Philosophie I, op. cit. p. 3-28.

8 A verdade do conceito é onipotente, supera em si toda e qualquer verdade, isto é, reduz toda verdade das diferentes dimensões do real à verdade do conceito. Cf. H-G. Gadamer, Wahrheit und Methode, p. 94.

9 Neste sentido, ela representa a plena autotransparência do ser no saber absoluto. Cf. H-G. Gadamer, Wahrheit und Methode, p. 199.

10 Enquanto Hegel trabalha a dialética da razão como automediação total da razão, ele está para além de qualquer formalismo argumentativo como, por exemplo, o da sofistica. Sua dialética é por isto, também, contra a argumentação vazia do entendimento, o que ele chamava de "reflexão externa". A filosofia do espirito de Hegel levanta a pretensão de articular uma mediação total entre a história e o presente. Por isto, ela supera o formalismo e se põe na esfera da história. Cf. H-G. Gadamer, Wahrheit und Geschichte, p. 328. 
que já vem dos gregos. ${ }^{11}$ Já Aristóteles dá primazia ao lógos apophantixós em relação a todas as outras formas de fala precisamente porque ele tem como finalidade o revelar. Dai vem que sua lógica vai concentrar-se na "sentença predicativa", que marcou todo o ocidente e cuja hegemonia só bem recentemente foi reduzida através da lógica hermenêutica de H. Lipp e da teoria dos atos de fala de J. Austin.

Hegel radicaliza esta tradição aristotélica não só com o auxilio da dialética, mas, acima de tudo, por ter conceituado, em sua lógica, a própria estrutura lógica da dialética. As categorias lógicas estão presentes na linguagem de tal modo que a própria linguagem se movimenta na direção da lógica a fim de que seja possivel pensar explicitamente as categorias que, de forma natural, atuam na linguagem. A lógica se revela, assim, como a realização plena da própria linguagem ${ }^{12}$ na medida em que o pensamento perpassa e conduz para a autoconsciência todas as determinações de pensamento que estão presentes na linguagem e que atuam em sua lógica natural.

A pergunta de Gadamer a Hegel é se a linguagem verdadeiramente é apenas uma lógica instintiva que ainda não chegou à consciência plena de si. Para Gadamer, de nenhum modo pode-se reduzir a lógica natural, que subjaz à gramática de qualquer língua, à função de ser uma forma prévia da lógica. De fato, a lógica tradicional, anterior a Hegel, é uma ciência puramente formal, o que não é o caso da lógica de Hegel, que tem pretensões ontológicas, ${ }^{13}$ o que conduz a conseqüências não previstas por Hegel: já nas diferentes formas de fala se encontram antecipações lógicas que articulam os esquemas de nosso acesso lingüístico ao real.

Portanto, o instinto lógico, presente na linguagem enquanto tal, não se esgota em ser uma forma prévia da conceituação que ocorre na lógica. O que vale para a construção da lógica, ou seja, que a exposição das categorias já utiliza e pressupõe as categorias que ela pretende inferir dialeticamente, vale também não só aqui, mas para toda relação entre palavra e conceito. Também vale para a palavra que não há começo num ponto zero e não é por acaso que a dedução dialética das categorias em Hegel é mais convincente, quando ele acrescenta origens históricas da palavra. Conceitos só são em sua função e esta função é permanentemente marcada pela lćgica natural da linguagem. O que a linguagem, falando, deixa ser é o ser, porém não no sentido hegeliano da imediatidade abstrata, mas antes no sentido do que Heidegger chama Lichtung, que contém ao mesmo tempo revelação e ocultamento.

A lógica de Hegel se revela a partir daqui como portadora de um lado só da verdade, o da determinidade plena do conceito, deixando totalmente de lado o mo-

11 Cf. H-G. Gadamer, Die Idee der Hegelschen Logik, p. 80.

12 Assim como a liberação da linguagem, pois, segundo Gadamer, a experiência do pensamento é concebida como a dialética do conceito, que levanta a pretensão de libertar-se plenamente do poder da linguagem. Cf. H-G. Gadamer, Wahrheit und Methode, p. 440.

13 Para Gadamer, Hegel, em vinculação com Platão, concebe o desenvolvimento dialético do pensamento como uma ação da própria coisa, ou seja, a dialética é o movimento da própria coisa experimentado pelo pensamento, o que implica um mútuo pertencer de pensamento e ser. Cf. H-G. Gadamer, Wahrheit und Methode, p. 439 e ss. 
mento do ocultamento ${ }^{14}$ e, por esta razão, ela é parcial. ${ }^{15}$ Mas para Gadamer, o próprio Hegel aponta em sua lógica para um além da própria lógica, pois o lógico não é a totalidade de todas as determinações de pensamento, mas a dimensão que subjaz a toda posição de determinações de pensamento. ${ }^{16}$ Hegel chama isto de "o especulativo"e fala da "sentença especulativa", ${ }^{17}$ que constitui o termo médio entre a tautologia e a auto-superação na determinação infinita. Precisamente aqui, para Gadamer, está a enorme atualidade de Hegel, porque a sentença especulativa não é a proposição enquanto linguagem. Nesta sentença não está somente em questão a tarefa objetivante da explicação dialética, mas também o limite do próprio movimento dialético, pois, embora, de acordo com a forma exterior, a sentença especulativa seja um juizo, ou seja, a atribuição de um predicado ao sujeito, na realidade o movimento da determinação não se faz aqui vinculado à base firme do sujeito, mas vai além dele, pois aqui o predicado é que é a substância, o sujeito passou para o predicado e com isto foi superado. A forma da sentença se destrói a si mesma na medida em que a sentença especulativa não diz algo de algo, mas manifesta a unidade do conceito. A dialética, a partir daqui, nada mais é do que a expressão do especulativo. ${ }^{18}$

Na sentença especulativa, o pensamento está em si mesmo: assim como a palavra que um diz está relacionada com o contínuo do entendimento intersubjetivo a partir de onde ela se determina, assim também a sentença especulativa aponta para uma totalidade de verdade, sem que ela mesma possa ser esta totalidade ou possa dizê-la. Este todo, que não é ente, Hegel pensa como a reflexão em si através de que ele se mostra como a verdade do conceito. Enquanto que na tendência para o lógico o conceito é pensado como a determinação plena do indeterminado e se plenifica como um lado da linguagem, o estar-em-si da reflexão contém uma correspondência permanente, que confunde, para o estar-em-si da palavra e da obra de arte, onde a verdade está abrigada e com isto se aponta para aquela concepção de verdade que Heidegger tenta pensar como "evento do ser" e que abre o espaço para todo conhecimento como para toda reflexão. ${ }^{19}$

14 Cf. E. Tugendhat, Der Wahrheitsbegriff bei Husserl und Heidegger, Berlin, 1967. E. Stein, Seminário sobre a verdade. Lições preliminares sobre o parágrafo 44 de "Sein und Zeit", Petrópolis, 1993.

15 A lógica de Hegel significa a mais radical submissão da linguagem à proposição, o que está em profunda contraposição à essência da experiência hermenêutica e com a linguicidade da experiência humana do mundo. Na verdade, Hegel percebeu o caráter especulativo da linguagem, mas o que interessa a Hegel na linguagem é o jogo reflexivo das determinações de pensamento e elevá-lo, através da mediação dialética, à totalidade da autoconsciência do conceito. Numa palavra, a dialética hegeliana permanece na perspectiva da proposição e não atinge a dimensão da experiência lingüística do mundo. Cf. A. C. Marçal, op. cit. p. 271.

16 Precisamente porque o evento lingüistico da fala e do entendimento vincula o dito com a infinitude do não-dito na unidade do sentido é que Gadamer contrapõe o entender-se e a palavra poética, que exprimem o especulativo da linguagem, à proposição teórica. Cf. A. C. Marçal, op. cit. p. 272.

17 Cf. H-G. Gadamer, Die Idee der Hegelschen Logik, p. 83.

18 Cf. H-G. Gadamer, Wahrheit und Methode, p. 442-443.

19 No entanto, em Hegel a sentença especulativa é para ser superada no saber absoluto e nisto Gadamer não pode seguir Hegel, pois apesar do processo infinito de formação do conceito, o espirito humano é finito e só pode chegar discursivamente à unidade da coisa. Cf. a respeito da confrontação entre Gadamer e Hegel a respeito da sentença especulativa: W. Schulz, "Amerkungen zur Hermeneutik Gadamers", in: Hermeneutik und Dialektik I, Tübingen, 1970, p. 307 e ss. A. C. Marçal, Das 
Neste sentido, a dimensão do lógico não é propriamente o espaço da alétheia, da manifestação radical do sentido, pois a linguagem, em que vivemos, é um elemento totalmente diferente da reflexão. ${ }^{20}$ Heidegger chama a linguagem de "casa do Ser": nela ocorre justamente o desvelamento do presente até a sentença objetivante, mas o "Ser mesmo", que nela tem seu lugar, não é enquanto tal revelado, antes permanece o essencialmente oculto no seio de todo desvelamento que ocorre na linguagem, tão oculto quanto a própria linguagem no falar. ${ }^{21}$ Nesta perspectiva a lógica hegeliana emerge como a plenificação conseqüente de uma tradição que vem de muito longe e que não tematiza esta dimensão mais originária.

No entanto, a grandeza de Hegel está justamente em que todo seu pensamento é um permanente apontar para esta dimensão. Não aponta a lógica do conceito que se desenvolve necessariamente para além de si mesma, ou seja, na direção da lógica natural da linguagem? Se a lógica de Hegel tematizasse esta referência constante à linguagem natural, ${ }^{22}$ ela se reaproximaria da dialética de Platão. Assim, como ela está, ela significa uma realização esplêndida da tarefa de fazer do lógico o fundamento da objetivação universal. Mas a linguicidade de todo pensar permanece uma tendência contrária como desafio para o pensamento. ${ }^{23}$ Quanto mais radicalmente o pensamento objetivante reflete sobre si mesmo e desenvolve em si a experiência da dialética, tanto mais claramente ele aponta para aquilo que ele não é. A dialética tem que ceder lugar à hermenêutica. ${ }^{24}$

Para Gadamer, a crítica da hermêutica à dialética se situa na tradição da crítica à filosofia da subjetividade. Sua especificidade é tematizar três ingenuidades típicas do pensamento do idealismo alemão: ${ }^{25}$

1. A ingenuidade da posição. Toda a lógica ocidental se concentrou, desde Aristóteles, no conceito da sentença, desprezando todas as outras formas da fala. A sentença pura corresponde à percepção pura e a crítica ao caráter abstrato de am-

Problem einer transzendentalen Hermeneutik in "Wahrheit und Methode" von H-G. Gadamer (mimeo), Frankfurt am Main, 1977, p. 269 e ss.

20 Gadamer fala da "dialética da palavra": cada palavra, na medida em que ela pertence ao todo de uma língua e com isto tem uma relação com o todo do ser, exprime, também, com a visão de mundo subjacente, algo não dito. Cf. H-G. Gadamer, Wahrheit und Methode, p. 434.

21 Cf. H-G. Gadamer, Die Idee der Hegelschen Logik, p. 84.

22 Ele redescobriria a finitude essencial do ser humano e compreenderia que o saber absoluto é inatingivel e que a compreensão é um inserir-se num evento de tradição, no qual o passado e o presente se medeiam permanentemente. Cf. H-G. Gadamer, Wahrheit und Methode, p. 274-275. H. Ineichen, Philosophische Hermeneutik, Freiburg/München, 1991, p. 188.

23 Dai a distinção feita por R.Wiehl entre fenomenologia, dialética e hermenêutica. A fenomenologia é menos uma teoria do que um método, que perscreve a toda teoria como atingir os respectivos objetos em si mesmos. A dialética é uma unidade móvel de teoria e método. A hermenêutica nem é teoria nem método no sentido estrito da palavra, porque se entende a si mesma como expressão de uma compreensão originária, que subjaz a qualquer distinção entre teoria e método. A esta compreensão originária se manifesta sempre um mundo no todo e isto previamente a qualquer conhecimento objetivo. Cf. R. Wiehl, "Begriffsbestimmung und Begniffsgschichte. Zum Verhältnis von Phnomenologie, Dialektik und Hermeneutik", in: Hermeneutik und Dialektik I, ed. por. R. Bubner/K. Cramer/R. Wiehl, Tübingen, 1970, p. 170-171. che Hermeneutik, ed. por H-G. Gadamer/G. Boehm, Frankfurt am Main, 1976, p. 316. 
bas foi radicalizada através da positura transcendental-ontológica de Heidegger. Por exemplo, Heidegger mostrou que o conceito de "fato", que corresponde à percepção pura como também à sentença pura, não passa de um "pré-conceito ontológico", pois nunca pode haver uma simples constatação de fato. Só algo que é visto a partir de antecipações (pré-conceitos vai dizer Gadamer) pode ser compreendido . No entanto, que as antecipações, que são condição de possibilidade da compreensão, possam também ser fonte de malentendidos, isto é uma forma de ser em que a finitude do ente finito "homem" se faz manifesta.

Gadamer é de opinião que ele mesmo levou até as últimas conseqüências esta concepção de Heidegger na medida em que ele mostrou que nós tentamos compreender o que foi significado por um autor em seu sentido. Porém, este "em seu sentido" não pode querer dizer como o autor mesmo significou. Isto quer dizer que compreensão vai além daquilo que é subjetivamente significado pelo autor e talvez sempre vá além. Ninguém pode imaginar que a consciência subjetiva dos agentes e dos participantes nos acontecimentos capte de fato a significação histórica de suas ações e dos eventos. Desde Hegel, sabemos que a história segue seu curso para além da autoconsciência dos indivíduos. Há, portanto, uma totalidade de sentido que é previamente dada a todo conhecimento reflexo. O ser que é compreensível é o ser que se dá no mundo do sentido e da palavra e isto antecede o conhecimento que se articula em sentenças predicativas, onde se situa a dialética hegeliana. ${ }^{26}$

2. A ingenuidade da reflexão. Aqui o movimento fenomenológico deu contribuições fundamentais para a crítica ao espírito subjetivo, hegemônico no idealismo alemão. A princípio parece que o espírito refletente é o espírito livre enquanto tal: No voltar-se sobre si mesmo ele é totalmente livre. O idealismo alemão considerou este "estar-presente-a-si-mesmo" (Bei-sich-selbt-Sein) do espírito enquanto "estadode-ação" (Tathandlung) em Fichte e enquanto "saber absoluto" em Hegel como a forma suprema de realização do ser humano. Mas já que a categoria de posição foi submetida a uma crítica radical, a esta concepção da realização do ser humano é tirado qualquer fundamento. Isto significa dizer que nem toda reflexão é objetivante; antes, existe reflexão que, no ato de efetivar uma "intenção", se volta sobre si mesma, sobre sua realização. O meu ouvir de som me é também consciente, uma posição já defendida por Aristóteles e retomada na modernidade por F. Brentano, o professor de E. Husserl. Gadamer pretende com dois exemplos mostrar o papel que este problema desempenhou na filosofia de nosso século. ${ }^{28}$

Em primeiro lugar na categoria de "situações-limite" de K. Jarspers. Situaçõeslimite são aquelas situações na vida humana em que a possibilidade de orientação através das forças da ciência fracassa e onde as coisas dependem de cada um e por esta razão emerge aquilo que permanece oculto na aplicação funcionalista da ciência para a dominação do mundo. Há muitas destas situações, Jarspers cita sobretu-

26 Segundo Gadamer, para o fenômeno hermenêutico, o ouvir tem primazia, pois o ouvir é o caminho para o todo, pois ele consegue ouvir o logos. Cf. H-G. Gadamer, Wahrheit und Methode, p. 438.

27 De acordo com a tradução de R. R. Torres Filho, em: $O$ espírito e a letra. A crítica da imaginação pura em Fichte, São Paulo, 1975, p. 68.

28 Cf. H-G. Gadamer, Die philosophischen Grundlagen des 20. Jahrhunderts, p. 320 e ss. 
do duas: a morte e a culpa. Nelas o homem se comporta de tal modo que aí ele se encontra todo. É isto o que é propriamente existir, isto é, a emergência do que cada um é propriamente e o decisivo aqui é que esta emergência não é algo emocional, mas um tornar-se transparente. Isto nada tem a ver com a reflexão objetivante, mas exige um tipo de saber que não provém das possibilidades anônimas da ciência.

Heidegger, por sua vez, acolheu esta problemática em suas considerações fundamentais sobre o sentido do Ser. O objetivo central de Heidegger, que não foi entendido, era pensar a essência da finitude não mais negativamente, mas justamente reconhecer, positivamente, na finitude, a estrutura fundamental da existência humana. Finitude significa temporalidade, então, a essência do eis-aí-ser é a historicidade. A compreensão é, por isto, não um ato da subjetividade, mas uma forma de ser. A partir daqui, Gadamer mesmo vai entender a compreensão como um evento e, neste contexto, insistir que não somente a compreensão é sempre acompanhada por um saber não objetivante, mas que, de modo algum, pode-se compreender adequadamente a compreensão entendendo-a como uma consciência de, porque o todo da execução da compreensão se insere no evento e é por ele perpassado. Não acontece na compreensão o estar-em-si da reflexão, pois ela é fundamentalmente marcada pela historicidade de nossa existência.

3. A ingenuidade do conceito. O leigo em filosofia, quando se pergunta, hoje, pelo que é específico da filosofia, tem a impressão de que filosofia tem a ver com a definição dos conceitos em que o homem pensa. Na realidade, esta opinião é marcada pela tradição nominalista hegemônica nos últimos séculos para quem a linguagem é, sobretudo, uma espécie de uso de sinais. O ideal, neste contexto, é a introdução de uma linguagem artificial que seja capaz de afastar todas as ambigüidades da linguagem comum e, assim como pretendia o círculo de Viena, desmascarar os falsos problemas da metafísica.

No entanto, o segundo Wittgenstein percebeu que o ideal da linguagem artificial é contraditório, porque qualquer linguagem é sempre uma ordem, uma vez que a função própria da linguagem é tornar possível o entendimento e que, portanto, os falsos problemas da filosofia não são falhas da linguagem, mas falsas dogmatizações metafísicas do pensamento. A linguagem é um jogo, uma forma de interpretação do mundo que precede toda e qualquer reflexão e este é exatamente o ponto em que o pensamento fenomenológico em Heidegger se vai desenvolver, reconhecendo que todo pensamento está situado no caminho da linguagem, tanto como limitação como possibilidade.

A partir daqui se articulou em nosso século uma crítica à consciência subjetiva, na medida em que se insistiu na íntima vinculação entre linguagem e conceito assim que, hoje, no tema filosófico da linguagem, se encontram ciência e experiência de mundo. Daí por que, a filosofia tem, hoje, segundo Gadamer, três grandes interlocutores: a) O pensamento dos gregos, que para nós é paradigmático, porque, tendo percebido a íntima vinculação entre palavra e conceito, puderam resistir ao dogmatismo do conceito e à injunção do sistema; b) A filosofia de Kant que, con- 
vincentemente, distinguiu entre "conhecer" e "pensar", onde a experiência não mais constitui a esfera de legitimação; c) Hegel, porque o conceito de espírito, ${ }^{29}$ que Hegel renovou a partir da tradição cristã do espiritualismo, subjaz a toda a crítica ao espírito subjetivo da época pós-hegeliana. O conceito de espírito, que transcende a subjetividade do ego, tem sua verdadeira correspondência no fenômeno da linguagem que, cada vez mais, se põe no centro da filosofia contemporânea. O fenômeno da linguagem contém o que é adequado à nossa finitude, ou seja, é infinito como o espirito, mas finito como qualquer evento.

Para Gadamer, o desmascaramento destas três ingenuidades da filosofia da subjetividade, de que Hegel é a expressão suprema, nos aponta para algo fundamental: a constituição do sentido não é obra da subjetividade isolada da história, mas só é compreensivel a partir de nossa pertença à história. ${ }^{30} \mathrm{~A}$ existência humana não pode superar sua facticidade originária. É no horizonte da tradição de um todo de sentido que compreendemos qualquer coisa, o que manifesta que não somos donos do sentido. ${ }^{31}$ A filosofia enquanto hermenêutica pretende ser hermenêutica da finitude, ${ }^{32}$ de nossa historicidade originária, o que implica compreender o sujeito que compreende a partir de sua inserção na história. ${ }^{33}$ Isto revela o ideal do saber absoluto como pura ilusão, já que a história precede e perpassa toda nossa compreensão. A "onipotência da reflexão", que é o específico da filosofia moderna e chegou a sua plenitude na lógica hegeliana, é quebrada por uma realidade que não é mais simplesmente capturada pela reflexão. O sujeito já desde sempre se experimenta a si mesmo no seio de um mundo de sentido historicamente gestado ao qual ele pertence e que nunca pode ser reduzido a seu objeto, pois é antes o horizonte a partir de onde ele compreende qualquer coisa. A herme-

29 Para Gadamer, em Hegel, o ser do espirito é, essencialmente, vinculado à idéia de "formação" (Bildung). Para Hegel, a essência formal da formação é a elevação à universalidade. Todo indivíduo, que se eleva ao espiritual a partir de seu ser natural, encontra na linguagem, no costume, nas instituições de seu povo, uma substância pré-dada, de que ele, como no aprender a falar, tem que fazer sua. Assim, o indivíduo está sempre no caminho da formação e no caminho de "superar" sua naturalidade na medida em que o mundo em que ele cresce é formado na linguagem e nos costumes. Cf. H-G. Gadamer, Wahrheit und Methode, p. 9 e ss.

30 W. Schulz interpreta o pensamento de Gadamer como continuação da superação da filosofia da subjetividade enquanto historificação da razão como ela ocorreu em Heidegger. Para Heidegger, a linguagem, na forma do diálogo, é o próprio evento da história. Isto significa dizer que história e evento são inseparáveis. A história se tornou o próprio sujeito. Daí por que história, linguagem, diálogo e jogo são grandezas cambiáveis. Cf. W. Schulz, op. cit. p. 311.

31 A insistência, por parte da hermenêutica, de nossa dependência em relação à tradição, à história que atua em nós, pode levar a uma contraposição pura e simples com o espírito crítico. Cf. R. Bubner, "Philosophie ist ihre Zeit, in Gedanken erfasst", in: Hermeneutik und Dialektik I, p. 329 e ss. E. Stein, "Dialética e Hermenêutica", in: Síntese Nova Fase 29(1983)21-48. O. Pöggeler, "Dialektik und Topik", in: Hermeneutik und Dialektik II, p. 278 e ss. H-G. Gadamer, "Rhetorik, Hermeneutik und Ideologiekritik", in: Kleine Schriften I, p. 113-130.

32 Somos, em todo nosso conhecimento e em todo nosso pensamento, tomados previamente pela interpretação lingǘstica do mundo, na qual crescemos. A linguagem é o sinal de nossa finitude. Cf. H-G. Gadamer, "Mensch und Sprache", in: Kleine Schriften I, p. 97.

33 Cf. H-G. Gadamer, "Das Problem der Geschichte in der neueren deutschen Philosophie", in: Kleine Schriften I, p. 8 e ss. 
nêutica faz presente à consciência esta realidade histórica que atua em toda compreensão humana. A criticidade do pensamento não significa mais a transparência plena de um saber absoluto, mas a tomada de consciência de nossa historicidade, como experiência de nossa vida, condição de possibilidade de nosso conhecimento.

\section{B. O espaço aberto na Lógica para a hermenêutica: a crítica interna de Cirne Lima}

Cirne Lima, também, se situa no movimento de crítica ao sistema absoluto, que desde Schelling tem marcado o pensamento ocidental. Para ele o cerne destas objeções $^{34}$ é a eliminação da contingência e o necessitarismo daí decorrente. ${ }^{35}$ Daí o grande desafio de nossa época: repensar a "coisa" da filosofia de tal modo que a contingência seja posta em seu devido lugar para fazer justiça ao mundo dos fenômenos em que vivemos. ${ }^{36}$

A determinação da tarefa própria à filosofia se faz a partir da própria situação da filosofia, hoje, caracterizada pela fragmentação da razão. Em nossos tempos, o pluralismo das múltiplas razões substitui a razão una e sistêmica. "A unidade da razão dá lugar às múltiplas razões, a unidade do sistema é substituída pela pluralidade dos muitos subsistemas, um justaposto ao outro, sem que uma racionalidade abrangente os perpasse, ordene e hierarquize". ${ }^{37}$

Nesta perspectiva, a tarefa primeira do pensar, hoje, se revela como sendo a necessidade de destruição da metafísica ocidental que, a partir de diferentes matizes, se manifesta como o grande erro que, durante séculos, impediu a emergência da riqueza das diferenças que se revelam nos plúrimos jogos de linguagem sem que uma razão abrangente consiga reuni-las numa unidade mais alta. ${ }^{38}$ Numa palavra, parece que o relativismo e o ceticismo são as únicas atitudes possíveis num mundo que recusou o sistema, portanto, a unidade do pensar, do julgar e do valorar. Situamo-nos no mundo sem referenciais últimos, que é o preço pago pela superação de uma razão considerada dogmática ${ }^{39} \mathrm{e}$ isto, para os contemporâneos, constitui condição de possibilidade de uma vida aberta, livre e criativa.

34 Cf. C. R. V. Cime Lima, Sobre a Contradição, Porto Alegre, 1993, p. 106.

Cf. : C. R. V. Cime Lima, Contradição e Dialética. Ensaios sobre a tremenda força da contradição (mímeo), Porto Alegre, 1993, p. 11. "As grandes e, sob certo aspecto, definitivas objeções contra Hegel podem ser resumidas em duas grandes questões. Pergunta-se, primeiro, o que é, na verdade, dialética? Como entender o princípio de não-contradição? $\mathrm{Ou}$, em formulação mais contemporânea, como conciliar o pensamento analítico e o método dialético? Segundo, como evitar o necessitarismo do sistema que leva, na Filosofia do Estado, ao totalitarismo político (como, de fato, se viu no estalinismo) e que conduz, na Filosofia da História, ao fatalismo?"

Cf. C. R. V. Cirne Lima, Sobre a Contradição, p. 98.

Cf. C. R. V. Cirne Lima, Contradição e Dialética, p. 1.

Cf. C. R. V. Cime Lima, "Sobre a contradição pragmática como fundamentação do sistema", in: Síntese Nova Fase 55(1991)p. 595. "Hoje, garante-se, só nos restam cacos ou fragmentos. Seria ilusório pretender, com eles, reconstituir ou reconstruir o mosaico de uma razão una, universalmente válida, que faça sentido e dê, assim,sentido uno e unificante a nossas vidas e à História".

39 Cf. C. R. V. Cirne Lima, "Filosofia e Sistema" (Entrevista) (mimeo), Caxias do Sul, 1992. "Temos, assim, na Filosofia Contemporânea, duas linhas de pensamento nitidamente caracterizadas. A primeira 
Para Cirne Lima este é o grande erro de nosso mundo pós-moderno, ${ }^{40}$ mas isto não significa para ele que esta postura não seja ao mesmo tempo o grande desafio $^{41}$ para o pensamento nos dias de hoje, ${ }^{42}$ ou seja, a questão fundamental, em nossos dias, é perceber que esta postura é insustentável, porque é impossivel pensar a multiplicidade sem que esta pressuponha a unidade; porém, a unidade deve ser pensada de tal forma que a multiplicidade não desapareça, eliminada por uma unidade que destrói as diferenças. Não se pode suprimir nem a unidade, nem as diferenças: "sem todo não há partes, sem o uno não há o múltiplo".

"A tarefa da filosofia, hoje e sempre, é de apontar para essa totalidade, sempre pressuposta e existente, a partir da qual e na qual cada parte possui seu sentido particular e, dessa forma, sua razão de ser". ${ }^{43}$ Toda filosofia repousa aqui: pensar a unidade fundamental, onde as diferenças emergem em seu sentido. ${ }^{44}$ Trata-se de tematizar uma razão abrangente, que é o universal em que todo particular se insere e do qual e no qual recebe sentido. ${ }^{45}$ A conciliação da unidade e da multiplicidade foi e continua sendo a tarefa maior da filosofia.

Isto significa afirmar que a filosofia só pode existir verdadeiramente como sistema; mas se são levadas a sério as objeções dos pós-hegelianos, isto implica um sistema aberto, em que, por um lado, se tematize a totalidade na qual as particularidades são inseridas e compreendidas, mas, por outro, que esteja aberto a muitas outras particularidades, já que o sistema nunca pode ser exaustivo, acabado.

Neste sistema, a afirmação de entrada é que a filosofia trata do absoluto, pois a afirmação que parece destruir todo absoluto o repõe: tudo é relativo, porém, pre-

vem de Descartes, passa por Espinoza, por Leibnitz, pelo Idealismo Alemão e por todos os tipos de Marxismo e defende a unidade da razão. A outra linha, numa primeira etapa, nega a razão e tenta introduzir a irrazão mas, ao descobrir que isso não é possível, implanta a pluralidade das múltiplas razões, dos muitos subsistemas, dos muitos jogos de linguagem".

40 Cf. C. R. V. Cirne Lima, Contradição e Dialética, p. 7. "Este é, em minha opinião, o grande erro de nosso mundo pós-modemo. Pois não pode haver multiplicidade sem que esta pressuponha a unidade e, dentro nela, se instaure; não há fragmentos sem a unidade da qual e na qual os fragmentos se desmembram e são aquilo que são, a saber, fragmentos. Isso no-lo ensinou Platão no diálogo Pamênides.

41 Neste sentido, pode-se afirmar que Cirne Lima leva extremamente a sério a afirmação de Gadamer de que o reconhecimento da finitude e da historicidade transformou, essencialmente, a tarefa da metafisica ocidental.

42 Cf. E. Luft, Para uma crítica interna ao sistema de Hegel, Porto Alegre, 1995, p. 180. "Cirne-Lima incorpora, aqui, toda a tradição de críticos que, desde o Schelling, tardio, passando por Nietzsche e todo o esfacelamento da razão em toda a filosofia pós-moderna, até as concepções mais atuais, vê ser totalmente improdutiva uma volta pura e simples à filosofia hegeliana sem a sua crítica aguda e reformulação. É a incorporação dessa visão crítica que revelará de forma tão contundente o problema da contingência". Cf. C. R. V. Cirne Lima, Contradição e Dialética, p. 8.

44 Nesta perspectiva, a filosofia não nega as múltiplas razões, mas é sua tarefa tematizar uma razão que perpassa todas as outras e que lhes dá unidade. A tarefa própria da filosofia, desde os gregos, é dar as razōes primeiras-últimas de tudo.

45 Já Hegel vira com clareza que o específico da "Filosofia real" era procurar o universal ínsito no particular, pois filosofia busca sempre o universal que constitui o particular e do qual ele adquire sentido. A Filosofia real continua vendo o todo, mas se detém em cada particular. Cf. C. R. V. Cirne Lima, "A Lógica do Absoluto", in: Sintese Nova Fase 63(1993). 
cisamente por ser relativo, aponta para um absoluto sem o qual ele não pode nem existir nem ser pensado. ${ }^{46}$ Portanto, se algo existe, existe também o absoluto. Ora, algo existe, logo o absoluto existe, por isto demonstrar a existência de Deus é uma perda de tempo. O próprio ato de fala, que nega o absoluto, se articula como uma proposição universalmente válida e, assim, pragmaticamente afirma e repõe a pretensão de validade, conseqüentemente, de absolutidade.

O problema filosófico central hoje, para Cirne Lima, se articula nas seguintes alternativas: ${ }^{47}$ 1) $\mathrm{O}$ absoluto existe, nós existimos, logo, nós e somente nós somos o absoluto, nada existindo no universo que seja relativo. 2) O absoluto existe e nós existimos; ora, nós somos completamente relativos; logo, existe um outro ser totalmente transcendente a nós que é o absoluto. 3) O absoluto existe, nós existimos, como relativos e contingentes. Logo, existe, transcendente a nós, mas simultaneamente imanente em nós, um absoluto que, sendo em nós, é sempre também mais do que nós. ${ }^{48}$

Precisamente aqui se põe a proposta corretiva do sistema hegeliano, que se centraliza na pergunta: "se o Absoluto em sua totalidade, ou seja, no todo de seu movimento processual que é tanto lógico como ontológico e no qual ele se desenvolve primeiro logicamente (a Lógica) e depois realmente (a Filosofia Real) pode ser pensado sem uma explosiva contradição como sendo ao mesmo tempo absolutamente necessário e como absolutamente contingente" ${ }^{49}$

Depois da fragmentação da razão, a reflexão filósofica, num primeiro momento, parte da dúvida universal para, através da mediação da contradição performativa, ${ }^{50}$ termatizar os princípios que regem o pensar, o falar e o ser. ${ }^{51}$ Para Cirne Lima este procedimento chega a três princípios que determinam e ordenam tudo: ${ }^{.52}$

1. O princípio de identidade, que diz e afirma como verdadeiro que A é A. Neste princípio estão implícitos três sub-princípios: a) a identidade simples, aquela que não pode ser ulteriormente explicada, que significa que algo é destacado de seu pano de fundo e determinado como algo; b) a identidade iterativa, quando ao primeiro $\mathrm{A}$ se acrescenta um segundo $\mathrm{A} ; \mathrm{c}$ ) a identidade reflexa, que é a expressão

46 Cf. C. R. V. Cime Lima, Sobre a contradição, p. 92 . "O núcleo duro dessa argumentação è o mesmo que encontramos no diálogo Parmênides de Platão: se há partes, então necessariamente há um todo do qual as partes são aquilo que são, a saber, partes. Assim também com o relativo. Pode haver coisas relativas; mais ainda, tudo pode ser relativo, exceto este fato e esta constatação de que tudo é relativo".

47 Cf. C. R. V. Cime Lima, Contradição e Dialética, p. 17.

48 Cf. C. R. V. Cirne Lima, Filosofia e Sistema, p. 35. "Hegel evidentemente queria fazer uma síntese do finito e do infinito. Ele pega o Deus da velha metafísica, que era transcendente e estava fora do mundo, e o coloca no âmago das coisas; o infinito é posto como a interionidade das coisas finitas. Assim, o infinito entra na constituição do mundo e das coisas. Infinito e finito, agora, não estão mais em oposição de exclusão e, sim, de inclusão".

49 Cf. C. R. V. Cime Lima, Sobre a Contradição, p. 96.

50 Que é, para Cime Lima, o motor da dialética. Cf. C. R. V. Cime Lima, Sobre a Contradição, p. 108.

51 Cf: C. R. V. Cime Lima, "Sobre a contradição pragmática como fundamentação do sistema", in: Sintese Nova Fase 55(1991)595-616.

52 Cf. C. R. V. Cirne Lima, Sobre a contradição, p. 102 e ss; "Dialética e Evolução" (veja artigo 1, deste número de Veritas. 
plena da identidade e a partir daqui temos a distinção entre sujeito e predicado lógicos.

2. O princípio da diferença, quando ao A se acrescenta algo que não é apenas um mero A, aquilo que está sempre em oposição ao que é idêntico a si mesmo. ${ }^{53}$ Esta diferença pode ser contraditória ou contrária. Conceitos contraditórios são construídos sempre que há uma negação estrita do conceito inicial: A e Não-A. A diferença contrária existe quando se opõe a $A$ não o conceito abrangente Não- $A$, mas simplesmente algo diferente de A. Por esta razão, entre os contrários, há apenas uma diferença qualitativa e não quantitativa, como é o caso nos contraditórios. Assim, o campo dos contrários não é, por conseguinte, o universo das coisas, mas apenas um conjunto limitado. O importante é acentuar que o contrário não pode ser deduzido da identidade anterior, ele é algo que ocorre, que acontece, é algo contingente, é fruto do acaso. Com isto abrem-se perspectivas novas para o discurso: "Contingência e acaso constituem aqui naquilo que é diferente por oposição contrária uma ruptura com a identidade, e significam tanto um enriquecimento, como também um perigo para o discurso". ${ }^{54}$

3. O princípio da coerência ou da contradição a ser evitada. Postas a identidade e a diferença, se põe a questão se uma se ajusta e combina com a outra. ${ }^{55}$ Aqui precisamente vem uma das teses centrais do pensamento de Cirne Lima, que the possibilitará corrigir o sistema hegeliano e articular a concepção de um sistema aberto: o princípio de não-contradição não diz uma impossibilidade dura e sim um "dever-ser", ou seja, ele não diz que contradições são impossiveis, mas que contradições não devem existir. O princípio maior do pensamento e da realidade não diz um "é impossivel", mas um "dever-ser", ${ }^{56}$ ou seja, na raiz mesma do sistema está um operador modal deôntico, ${ }^{57}$ que depois se vai articular como ética.

A tradição do pensamento ocidental, quase sempre, entendeu a formulação aristotélica "é impossível" no sentido de uma necessidade logicamente estrita, rigorosa e dura ${ }^{58}$ contra a qual nem Deus, como diziam os medievais, poderia fazer algo. Aqui não não há exceções nem por princípio pode haver. No entanto, contra-

53 Trata-se, aqui, da multiplicidade que, para Cime Lima, é tão originária quanto a unidade. Cf. C. R. V. Cime Lima, Sobre a Contradição, p. 102-103. "Multiplicidade não pode, em última instância, ser reduzida à unidade; é, por igual, impossivel deduzi-la a partir da unidade. A multiplicidade tem, pois, sua razão suficiente em si mesma e não no princípio de unidade".

54 Cf. C. R. V. Cirne Lima, Dialética e Evoluçāo, p. 703.

55 Cf. C. R. V. Cime Lima, Sobre a Contradição, p. 103. "No curso e na formação do universo a combinaçăo de ambos os subprincípios, do principio da unidade [...] e do princípio da multiplicídade [...] obedece à lei mais alta da Lógica e da Ontologia, a saber, à lei de que não devem existir contradições".

56 Cf. C. R. V. Cirne Lima, Filosofia e Sistema, p. 22. "A Năo-Contradição, neste sentido, é um ideal sempre realizado parcialmente, mas nunca passivel de ser efetivado completamente".

57 O que significa dizer que as grandes leis que regem a natureza e a história são apenas leis do deverser.

58 Cf. C. R. V. Cirne Lima, Filosofia e Sistema, p. 15. "Quero levar a tradição adiante, precisando-a, tornando-a mais exata: o adynaton que comanda todo o Princípio de Não-Contradição é um operador deôntico. Ele é modal, sim, não no sentido usual, mas no sentido deôntico". 
dições faticamente existem, portanto elas podem existir, embora não devam existir $^{59}$ e precisamente aqui está o sentido universalmente válido deste princípio. Quem não o aceita nega a própria racionalidade do discurso e, na realidade, não diz nada, porque diz algo e, ao mesmo tempo, se desdiz. Mas se contradições existem o discurso racional implode a não ser que elas sejam trabalhadas e superadas.

Aqui temos duas possibilidades. No primeiro caso um dos pólos anula pura e simplesmente o outro, pois um é verdadeiro e o outro, falso. Neste caso, a racionalidade exige que se conserve a proposição verdadeira. Isto é algo que pode ocorrer muitas vezes, mas não sempre. A regra aqui é que duas proposições contraditórias não podem ser simultaneamente nem verdadeiras nem falsas. Assim, um pólo da oposição sempre elimina o outro.

A outra possibilidade é o caso das proposições contrárias. Se uma é verdadeira, a outra será falsa como no caso das contraditórias. Mas se uma é falsa, a outra poderá ser verdadeira ou igualmente falsa e precisamente aqui, para Cirne Lima, se põe a dialética, ou seja, no caso em que ambos os pólos tenham a seu favor argumentos concludentes de tal modo que não seja possível eliminar um dos contrários. Então, toda a tradição do pensamento dialético afirma, segundo Cirne Lima, que neste caso, é necessário considerar os dois opostos como igualmente unilaterais e falsos e, fazendo as devidas distinções, conciliá-los num plano mais alto. Aqui, os contrários não deixam de ser opostos, isto é, a diferença não desaparece, mas eles deixam de ser mutuamente excludentes e são conservados e conciliados. ${ }^{60}$ Se o princípio de não-contradição significa um dever-ser, então é este deverser que nos leva a trabalhar as contradições de tal modo que, em certos casos, elas possam constituir uma síntese num plano superior.

Este procedimento reflexivo nos mostra, em primeiro lugar, a resposta a uma das questões básicas com que se depara o pensamento dialético depois das objeções da tradição crítica pós-hegeliana, ou seja, a dialética, em nenhum momento, fere as regras de inferência trabalhadas pela lógica formal. Ao contrário, o pensamento dialético inclui o pensamento analítico como um de seus momentos necessários. A dialética trabalha precisamente com proposições contrárias, que são ambas falsas. Ora, a falsidade tanto da tese como da antítese, que é condição de possibilidade para que se possa dar o jogo de contrários, só pode ser demonstrada através do método analítico: trata-se de explicitar a contradição performativa aí presente. Aqui é o lugar do entrelaçamento necessário entre o "método dialético" e o "método analítico", que exerce um papel fundamental: é precisamente a demonstração da falsidade que impele o pensamento a prosseguir, pois do contrário a racionalidade do discurso estaria sendo abandonada.

Como prossegue o discurso? Como emerge a antítese? Aqui é o lugar do entrelaçamento entre "dialética" e "hermenêutica", numa contraposição à tese de Ga-

59 No fundo, a razão é essencialmente prática. Cf. C. R. V. Cime Lima, Filosofia e Sistema, p. 29. "[...] não dá mais para fazer a distinção entre razão teórica e razão prática. Ela é uma coisa só, mas é muito mais prática do que teórica".

60 Cf. C. R. V. Cime Lima, Sobre a Contradição, p. 95़. "Exatamente este é o sentido de aufheben, isto é, ambos os pólos, que num primeiro nível se opõem e se excluem, num nível mais alto são conciliados e unificados, sem que com isso um deles desapareça ou seja diluído em benefício do outro". 
damer para quem a dialética deve ceder lugar à hermenêutica por esta ser mais radical. Para Cirne Lima, há um lugar específico para a hermenêutica na dialética. Uma distinção básica entre analíticos e dialéticos é que os dialéticos não utilizam, como os analíticos, proposições bem formadas; então, em seus conceitos, sujeitos e predicados não estão desdobrados logicamente. Daí por que é impossivel, na dialética, construir aprioristicamente proposições contrárias. ${ }^{61}$ Assim, não se faz possivel, em dialética, distinguir, e esta distinção é fundamental pois é ela que vai dizer se há ou não dialética, contraditórios e contrários simplesmente a partir de sua forma sintática. É indispensável, então, lançar mão de conceitos completamente diferentes para exprimir os pólos contrários. E aqui entra a hermenêutica que já havia sido utilizada no primeiro momento de escolha da tese, pois a dialética não é uma construção apriórica, uma vez que "os predicados da proposição dialética não são, portanto, conceitos construídos a priori, e sim conceitos oriundos do espaço onde foram colocadas e onde se encontram todas as proposições" ${ }^{62} \mathrm{O}$ filósofo examina e escolhe um predicado que seja oniabrangente e simples para servir como a primeira proposição do sistema. Tudo isto é conseqüência do fato de que o princípio supremo foi entendido como um dever-ser, o que torna impossivel uma construção apriórica do sistema. Então, a hermenêutica emerge como um momento constitutivo do procedimento dialético, sem o qual, assim como o método analítico, embora por razões diferentes, o procedimento dialético não poderia acontecer.

Cirne Lima situa, na lógica hegeliana, o lugar determinado, onde esta releitura da lógica hegeliana se deve articular. É na lógica da essência, quando Hegel trabalha as modalidades. ${ }^{63}$ Hegel constrói seu argumento ${ }^{64}$ em três rodadas de tal forma que, em cada uma delas, o argumento se completa em sua circularidade a partir da imediatidade da tese, da negativa da antítese e da conciliação sintética de ambos os momentos. Em cada rodada há, portanto, uma estrutura básica que se repete.

No primeiro momento, trata-se da efetividade formal. O começo é constituído pela categoria da efetividade, que contém em si todas as categorias anteriores. Efetividade é o ser que se reflete como essência: a efetividade é ser. Ora, já a lógica tradicional sabia que o que é efetivo é possivel: a possibilidade nada mais é do

61 Cf. C. R. V. Cirne Lima, Sobre a Contradição, p. 111. "Oposições contraditórias de conceitos podem ser obtidas, em Lógica, de forma construtivista, bastando para isso antepor a um conceito determinado a negação; tais conceitos contraditórios não são, em sua construçãø, nem empiricos, nem contingentes. Mas conceitos contrários são algo que a gente encontra, já feitos e formados, na linguagem contingente e na realidade histórica; eles não podem ser feitos de maneira construtivista e, por isso, também não podem ser deduzidos".

62 Cf. C. R. V. Cime Lima, Dialética e Evolução, p. 708.

63 Isto é, no fim do segundo livro da Ciência da Lógica, onde Hegel faz a transição da substância absoluta de Espinoza precisamente para a categoria de auto-causação, que é a liberdade enquanto autodeterminação".

64 Para Cirne Lima, é importante ter presente que Hegel situava seu próprio pensamento como a síntese entre a posição de Espinosa e Kant. Cf. C. R. V. Cime Lima, Sobre a Contradição, p. 82. "A grande tarefa intelectual que Hegel se coloca é a de pensar o sistema de Filosofia de maneira que $0 \mathrm{Ab}$ soluto, nele, seja não apenas substância necessária, mas também sujeito moral livre. A dialética das modalidades com sua rede de inter-relaçöes entre possibilidade, contingência e necessidade deve ser a ponte que leva ao sujeito livre, ou, como Hegel mesmo diz, ao conceito livre". 
que a interioridade do que existe. Mas, a pergunta de Hegel vai além, segundo Cirne Lima, ou seja, trata-se para ele de se perguntar se é possível pensar uma possibilidade que vá além desta possibilidade ínsita no existente, uma questão para a qual não existe resposta tanto na lógica tradicional, quanto na lógica modal contemporânea.

A efetividade é ser e é, em primeiro lugar, o ato pelo qual e no qual pensamos e falamos. Ora, o ato de pensar movimenta-se, ele está a caminho, não chegou ainda à sua meta, que tem que ser pensada como possivel, pois um movimento na direção ao impossivel é um movimento na direção do nada, ou seja, não é um movimento. Isto significa uma nova forma de possibilidade, pois a meta não é simplesmente idêntica à efetividade inicial, mas the está em oposição. Cirne Lima chama atenção ao fato de que tal argumentação só se sustenta quando se refere ao fim último, pois movimento em relação a fins intermediários, empíricos não pressupõe a possibilidade de tais fins. O que há de novo, em todo este raciocínio, é que, aqui, emerge uma possibilidade que não é apenas um aspecto interno da coisa existente, mas externo: efetivo e possível são, aqui, opostos.

A partir daqui é possivel pensar duas sinteses. Nosso ato performativo de pensar está a caminho, ainda não pensa tudo, mas pensa algo, é, em si mesmo, uma realização parcial da meta, com um duplo caráter: por um lado, ele é efetividade, mas efetivação parcial de uma possibilidade. Portanto, este ato performativo que antecipa a totalidade do pensamento completo, é efetivo e possivel, a síntese de efetividade e possibilidade. Ele é contingência, pois "o contingente é este ser bifacial que, por um lado, é efetivo e, por outro lado, é possivel, é algo que poderia, por igual, não ser e não existir. A labilidade deste ser que, embora de fato exista como efetivo, oscila entre o poder-ser e o por-igual-poder-não-ser, essa é a principal característica do contingente" ${ }^{16}$

Portanto, este ato performativo de pensar é tanto efetivo como possivel. De forma alguma se pode dissolver a contingência que há aí, porque inclusive a tentativa de fazê-lo é um outro ato contingente, ou seja, outro ato de pensar que é igualmente contingente. Toda tentativa de dissolução esbarra sempre num outro ato de pensar e assim se percebe que este ato contingente é, também, necessário sem que com ísso deixe de ser contingente: "a contingência, sem se perder e sem ser completamente dissolvida, foi colocada em nível mais alto, no qual ela tem a necessidade como a outra metade de si mesma". ${ }^{66}$

$\mathrm{Na}$ segunda rodada, a efetividade real, Hegel repõe as mesmas posições só que, agora, os diversos aspectos não são considerados em si mesmos isoladamente, mas como interligados entre si e se acentua que as modalidades não são apenas do falar e do pensar, mas da realidade mesma, ou seja, aspectos objetivos da efetividade real, que é, portanto, realmente contingente e realmente necessária, isto é, necessariamente relativamente, enquanto de fato existe.

Ora, se toda efetividade real é relativa, então tudo é relativo; se tudo é relativo, é absoluto que tudo seja relativo, pois tudo pode ser relativo exceto este fato e esta

65 Cf. C. R. V. Cirne Lima, Sobre a Contradição, p. 89.

66 Cf. C. R. V. Cirne Lima, Sobre a Contradiçäo, p. 89. 
constatação de que tudo é relativo e assim se faz a passagem para a efetividade absoluta. Aqui está, para Cirne Lima, o coração do sistema hegeliano e nele se afirma que a necessidade absoluta é idêntica à contingência absoluta. ${ }^{67}$ Para Hegel se deve pensar esta identidade em analogia com a implicação lógica, como o nexo entre $\mathrm{o}$ antecedente e o conseqüente. O nexo é absolutamente necessário, as condições iniciais é que são contingentes. ${ }^{68}$

Para Cirne Lima, a questão fundamental é saber se a necessidade possui e pressupõe a contingência sempre e em todos os casos como a outra face de si mesma. A questão não se põe em relação a coisas realmente existentes, pois estas implicam, tanto do ponto de vista lógico quanto "ontológico, um momento real de necessidade e um momento real de contingência. O problema é saber se é, assim, também em relação ao absoluto em sua totalidade, ou seja, a questão é saber se todos os nexos do universo, como no conceito contemporâneo de ciência, apesar de ser contingente a condição inicial, são necessários e, portanto, se a contingência das coisas e a livre escolha do homem e sua responsabilidade ética são, em última instância, impossiveis.

É, precisamente neste lugar, que Cirne Lima propõe uma correção do sistema hegeliano e o faz aberto à contingência, à historicidade. A proposta de Cirne Lima é que a necessidade absoluta não seja entendida como um Müssen, como um ser necessário, mas como um Sollen, um "dever-ser". O dever-ser é uma necessidade, mas uma necessidade que abre o espaço para que as coisas possam ser de outro modo. Numa palavra, o dever-ser é uma necessidade que sempre pressupõe contingência. ${ }^{69} \mathrm{O}$ dever-ser emerge, para Cirne Lima, como a categoria sintética que guárda, conserva e supera, em partes iguais e proporções idênticas, contingência e necessidade. ${ }^{70}$

Isto significa dizer que o processo, como totalidade em movimento, é algo que se está fazendo e nós, parte dele, antecipamos seu fim. É precisamente o fim que está sendo antecipado em cada movimento, que executamos. ${ }^{71}$ Cada um deles é,

67 Para Cime Lima, o Hegel histórico é, a respeito da contingência real, no minimo profundamente ambíguo. Daí a necessidade de uma correção que desfaça esta ambigüidade. Cf. C. R. V. Cirme Lima, Sobre a Contradição, p. 99. Cf. J-M. Lardic, A contingência em Hegel, São Paulo, 1995.

68 Cf. C. R. V. Cirne Lima, Sobre a Contradição, p. 105. "O sistema e o método de Hegel - do Hegel histórico - por transformar em última instância toda contingência em necessidade, só admitem e reconhecem o processo rigorosamente necessário do pensamento que passa de uma etapa para outra etapa, de categoria para categoria, de figuração para figuração, sem que jamais haja, nisso, uma altemativa. A dialética e, assim, todo o sistema de Hegel avança de forma necessitária, em processo inelutável, como a seqüência de números em matemática".

69 Cf. C. R. V. Cime Lima, Filosofia e Sistema, p. 22. "Na Ontologia, tiro uma conclusão análoga: o ser necessário nunca é totalmente necessário, pois tem que ter, dentro de si, alguma contingência; ele nunca é tão absoluto que não tenha, dentro de si, alguma relatividade. Ou seja - e nisso concordo totalmente com Hegel - o ser absoluto tem que ter predicados negativos, claro que a serem superados e guardados. Mas existe negatividade dentro do absoluto, existe multiplicidade dentro do uno, existe contingência dentro do necessário".

70 Cf. C. R. V. Cirne Lima, Filosofia e Sistema, p. 14. "[...] uma boa ontologia é, desde sempre, deôntica. Ponho no começo do sistema uma ontologia que é, ao mesmo tempo, uma lógica e uma ética".

71 Cf. C. R. V. Cime Lima, Filosofia e Sistema, p. 38. "O fim da História é o eterno dia presente, em cada um de nós, em cada povo, em cada obra de arte, em cada religião. É uma Escatologia em que antecipamos o fim a cada momento que, com isso, fica eterno". 
pois, um resgate da totalidade que nunca está completa e acabada. Desta forma, o "processo total" é um processo em aberto no qual nós, através de nossas decisões, influimos e co-determinamos. Assim, "todos nós somos co-autores do sentido da História do Universo. Insignificantes, sim, mas verdadeiros co-autores". ${ }^{72}$ 